\section{Stamps of Various Shapes}

W

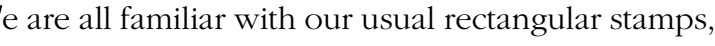
but several countries have produced more unusual designs. Such stamps are issued for decorative reasons or represent a particular object such as a football, a map of the country, or a lunar module.

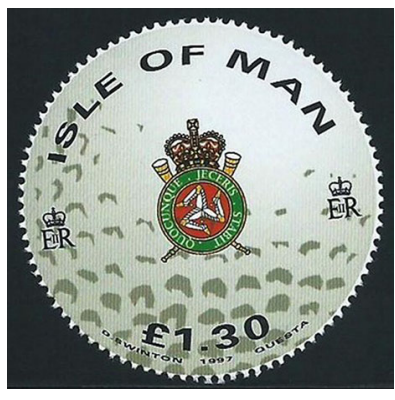

Circle

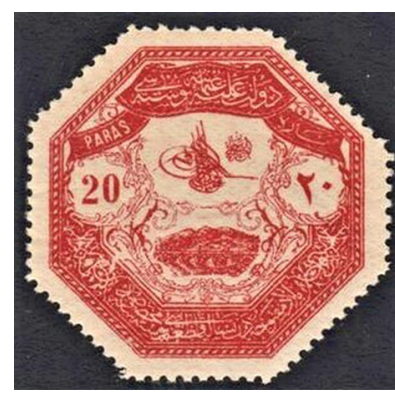

Octagon

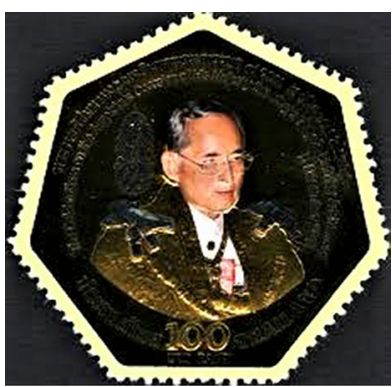

Heptagon
Many countries have issued triangular stamps, usually isosceles right-angled or equilateral. Scalene triangles are rare, with an early example from Colombia.

Although most four-sided stamps are rectangular, they can also take the form of parallelograms, rhombuses, and trapezoids (or trapezia if you are British). A few countries have produced pentagonal stamps; the Maltese ones are Christmas stamps that represent the crib at Bethlehem. Hexagonal stamps depicting beekeeping were issued by the Pitcairn Islands, and there are also unusual heptagonal and octagonal stamps.

Several countries have issued circular stamps, often to commemorate sporting events. A set of semicircular stamps was produced by Singapore, and one of elliptical stamps by Sierra Leone.

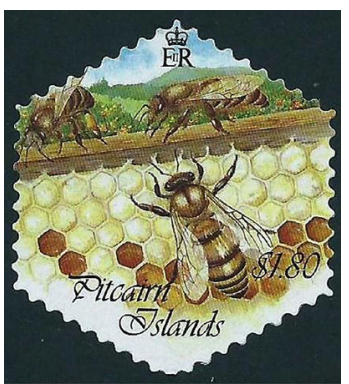

Hexagon
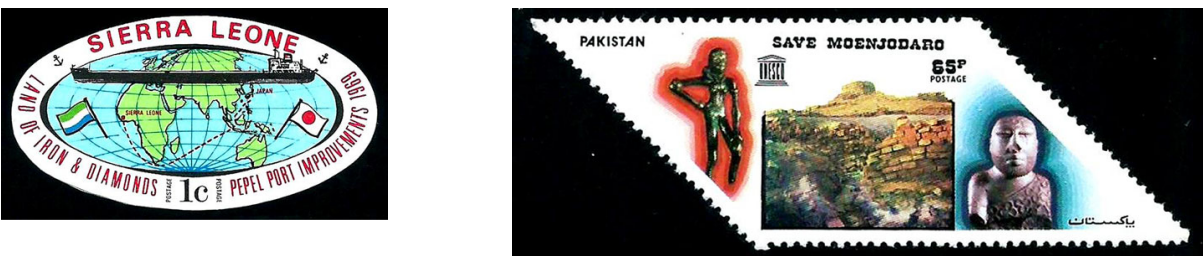

Parallelogram

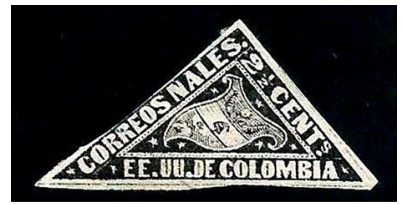

Scalene Triangle

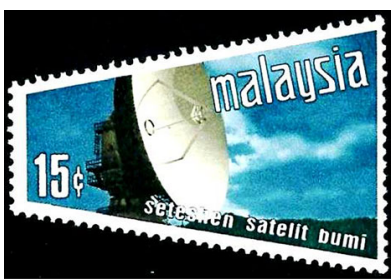

Trapezoid

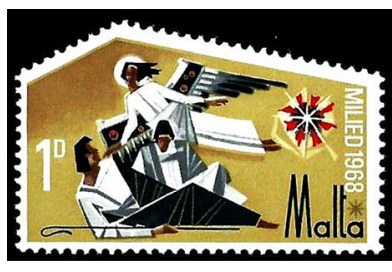

Pentagon

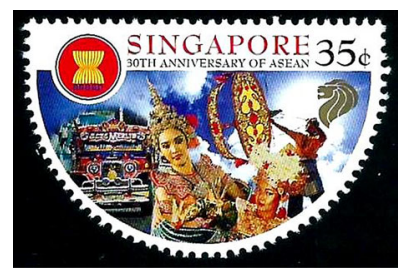

Semicircle
> Mathematical Institute

Andrew Wiles Building

University of Oxford, UK

e-mail: r.j.wilson@open.ac.uk
Publisher's Note Springer Nature remains neutral with regard to jurisdictional claims in published maps and institutional affiliations. 